\title{
Peer mentoring justice-involved youth: a training model to promote secondary desistance and restorative justice among mentors
}

\author{
Mayra Lopez-Humphreys and Barbra Teater*
}

\begin{abstract}
This article introduces a mentoring programme for justice-involved youth that utilises the unique and often overlooked resources offered by adults with a history of incarceration, and the innovative training model that aims to promote secondary desistance and restorative justice among the mentors. An examination of the generative role of peer mentoring and its overlap with restorative justice as a healing process that provides opportunities for offenders to make indirect amends that contribute to the social rehabilitation of their communities is presented. An overview of the history and anticipated aims of mentoring programmes for justice-involved youth is provided, followed by a discussion of the importance of secondary desistance in peer mentoring programmes and a review of the elements, conceptual underpinnings and anticipated benefits of the training programme for the mentors. The training programme is argued to offer approaches that support the primary and secondary desistance-orientated changes and the reparative work needed within the mentor.
\end{abstract}

Keywords: Peer mentoring, justice-involved youth, formerly incarcerated, secondary desistance, training programmes.

\section{Introduction}

The use of formal mentoring relationships as an effective intervention for addressing the needs of high-risk youth has significantly grown across the United States and the United Kingdom (England, Wales, Scotland and Northern Ireland) over the last two decades. More recently, a limited body of research has confirmed that peer mentoring with adults who were formerly incarcerated can

* Mayra Lopez-Humphreys is Associate Professor, Department of Social Work, City University of New York College of Staten Island, New York, United States of America. Barbra Teater is Professor, Department of Social Work, City University of New York College of Staten Island, New York, United States of America. Contact author: mayra.humphreys@csi.cuny.edu. 
reduce recidivism, enhance the prosocial protective factors of justice-involved youth and provide crucial restorative service contributions to under-resourced communities (Austria \& Peterson, 2017; Douglas \& Delgado, 2014; Maruna, 2016; Prince's Trust, 2008). However, outside of measuring reductions in recidivism, studies reporting on outcomes with adult mentors who were formerly incarcerated are minimal. Programme descriptions also offer little clarity on how to develop programmes and peer mentoring training models that address both the criminogenic-focused Risk Need Responsivity (RNR) concerns and provide a strengths-based, secondary desistance-orientation, which is a process of internal motivations and self-identity changes related to ceasing patterns of criminal behaviour (Maruna, 2001).

More broadly, the values and principles of restorative justice support desistance processes as interventions that require adults with a history of offending to work towards 'repairing the individual, relational and social harm' their offences have imposed (Walgrave, 2008: 21; Ward, Fox \& Garber, 2014). However, Marsh (2011) notes that for many adults who have served long-term prison sentences, opportunities to make direct amends with the individuals and communities that were victimised may no longer be possible. In such cases, peer mentoring programmes with justice-involved youth can provide restorative service opportunities for adults with a history of incarceration to make indirect amends through their efforts to prevent high-risk youth from continuing onto a similar path of lifelong criminal behaviour (Liem \& Richardson, 2014; Marsh, 2011). Equally important, Ward et al. (2014) suggest that there is a common incongruence of restorative justice principles in the literature. Definitions of restorative justice principles often describe a process of healing that is inclusive of the individual who has committed the crime; however, there is a dearth of literature on practices that address the harm that criminal behaviour has caused to the offender. A peer mentor training model that supports a secondary desistance-oriented change process could provide opportunities to address the reparative work needed within the individual who has committed a criminal offence and could identify specific ways in which the model assists mentors to participate in reparation towards the community. The mentor's engagement in such reparative work can also foster indirect amends that contribute to the 'social rehabilitation' of the communities they serve (Maloney, 2007). Carrying the trauma of abuse, neglect, incarceration and marginalisation, peer mentors are often 'wounded healers' who can empathise with the experiences of justice-involved youth, but are also in need of opportunities to engage in restorative justice practices that address the relational, the social and the individual harm caused by crime. This article presents a model for peer mentor training that specifically focuses on secondary desistance changes and the internal reparative needs of the mentors, which is anticipated to additionally create a pathway for the mentors' reparation towards the community.

This article introduces the Credible Messengers Institute training programme, which is a new mentoring training programme for adults who have a history of incarceration and will serve as mentors to justice-involved youth. The Credible Messengers Institute mentoring programme was developed and based 
upon the concepts and principles of secondary desistance, the strengths-perspective and restorative justice. The training model for the peer mentors is a unique attribute of the mentoring programme as it aims to promote the mentor's internal healing process through secondary desistance changes in the participant's human and social capital, psychological well-being and capacity for hope and generativity. The resources gained through the training programme are argued to support communitarian principles of restorative justice. For example, rather than being viewed as a 'threat' to a neighbourhood's resources, adults engaged in restitution via mentoring practices with youth can become crucial assets in the social rehabilitation of the communities they serve (LeBel, 2009). In introducing the peer mentoring programme and unique training model, this article will highlight how the programme is consistent with other peer mentoring programmes yet distinct and innovative in its aims and outcomes for peer mentors who were formerly incarcerated. This article will begin with a brief review of the history and aims of peer mentoring programmes and will then present the credible messengers mentoring programme and training institute, the unique elements of the training model and the anticipated reparative benefits of the training model to the peer mentor and will conclude with implications for future research and practice of peer mentoring with justice-involved individuals.

\section{The history of justice-involved youth and mentoring}

Current forms of mentoring programmes with justice-involved youth in the United States were initially developed in the early 1900s by large urban cities seeking formal approaches for addressing 'juvenile delinquency' through a separate juvenile court (Baker \& Maguire, 2005). In the 1992 Reauthorisation of the Juvenile Justice and Delinquency Prevention Act (JJDPA) of 1974, Congress added Part $G$ to include mentoring interventions that would receive funding through Juvenile Mentoring Program (JUMP), which is a federal programme administered by the Office of Juvenile Justice and Delinquency Prevention (OJJDP). In part, this addition to the JJDPA of 1974 was in recognition of mentoring and its value as a tool for reducing delinquent activity (Bilchik, 1998). A few recent studies have also confirmed that formal mentoring relationships offer valuable approaches for helping high-risk, justice-involved youth make the transition to a productive life in three specific areas: (1) reducing rearrests, (2) improving academic success and (3) increasing employment gains (Douglas \& Delgado, 2014; Tapia, Alarid \& Enriquez, 2013). For example, the results of a study with Youth Advocate Programs (YAP), a national youth-serving organisation connecting justice-involved youth with mentors, showed that 86 percent of youth participants did not have any returning arrests, and participants showed significant gains in academic performance and employment (Douglas \& Delgado, 2014).

Evidenced-based, justice-involved youth programmes integrating desisting adults as peer mentors are emerging in the United Kingdom (Huggins, 2010; Prince's Trust, 2008; Weaver \& Lightowler, 2012). In England, Foundation 4 Life (F4L) partnered adults who were incarcerated with high-risk, gang-involved 
youth. An evaluation of the F4L programme showed an almost 30 percent increase in participants' positive decision-making and consideration of the consequences of unlawful behaviour (Weaver \& Lightowler, 2012). Additionally, a survey of justice-involved youth living in the United Kingdom identified that 65 percent of youth believed that an experience with a mentor would support prosocial behaviours and 71 percent of youth specified that they would prefer a mentor who had experienced involvement with incarceration (Prince's Trust, 2008).

In the United States, beginning in the 1980s, former Black Panther Eddie Ellis was the first to describe desisting peer mentors as 'credible messengers'. As a result of sharing similar justice-involved life experiences, credible messengers could be influential in providing hard-to-reach, high-risk youth with support in transforming attitudes and behaviours around violence (Austria \& Peterson, 2017). By the mid-1990s, the OJJDP expanded its investment in the formal structuring of peer mentoring initiatives through the National Faith-Based Initiative for High-Risk Youth, which involved a ten-city research demonstration project mobilising adults who were incarcerated to engage high-risk youth (Bauldry \& Hartmann, 2004). Federal peer mentoring initiatives led to an expansion of state-funded, peer mentoring demonstration projects, including the New York state-funded South Bronx Community Connections (SBCC) initiative. The 3-year evaluation study of the initiative showed that high-risk juveniles participating in the SBCC's peer mentoring component were 33 percent less likely to have rearrests than the comparison group (Curtis, Marcus \& Jacobs, 2013). What appears to be missing from both programme development and evaluations of existing peer mentoring programmes are the anticipated and actual change outcomes for the peer mentors themselves, or any training programmes that address the personal harm experienced by justice-involved mentors. Programmes that foster and support secondary desistance changes, particularly among peer mentors, could be an innovative way to promote individual and social forms of restorative justice.

\section{The emergence of secondary desistance in peer mentoring models}

The concept of desistance is an emerging perspective in US practice, research and policy. According to Farrall and Calverley (2006), 'desistance-focused' and 'offender-focused' approaches are distinguished by where the emphasis of change is placed, and how the route to change is developed. Offender-focused approaches, which are the more common approaches within peer mentoring programmes for justice-involved youth, primarily target the reduction of the eight criminogenic risk/needs of the RNR model while also working to increase an individual's noncriminal behaviours (e.g. writing a risk avoidance plan) (Bonta \& Andrews, 2017). Although the models of desistance can be consistent with the aspects of the RNR approach, a primary desistance paradigm seeks to promote what personally motivates one's behaviours and experiences that lead to ceasing criminal behaviours (Maruna, 2001). On the contrary, secondary desistance change processes focus on strengths-based approaches that support a 'fundamental and intentional shift in the person's sense of self' (Maruna, 2001: 17). 
Maruna's (2001) seminal book, Making good: how ex-convicts reform and rebuild their lives, highlights the importance of providing restorative opportunities and generative roles that support secondary desistance. In his Liverpool desistance study with formerly incarcerated adults, Maruna (2001) compares and contrasts the narratives of formerly incarcerated adults who are desisting from crime with adults who continue their involvement in criminal behaviour. Through a narrative analysis of participants, this study provides an innovative strengths-based approach that offers a new direction for rehabilitation efforts with returning citizens.

\subsection{Linkages between restorative justice and secondary desistance}

From a restorative justice perspective, secondary desistance processes also encourage opportunities 'to make good' by participating in generative helping roles that contribute to the communities and individuals harmed by a person's actions. Maruna (2016: 295), a leading scholar on innovative paradigms for offender rehabilitation, has argued for a 'redemption-based justice model' that leverages the synergy between restorative justice and desistance perspectives:

[...] restorative justice suggests that 'giving back' is the right thing to do for victims and for society; whereas desistance theory has found that 'giving back' also has a beneficial role for individual wrong-doers because it allows them to better reintegrate into society.

The focus on the benefits to the mentors through their mentoring roles is not a new concept. Riessman (1965) acknowledged that the mere act and role of peer mentoring could lead to improvements to the mentor, which he termed the 'helper' therapy principle. The helper therapy principle notes two implications for the mentor: (1) a rehabilitative aspect for the mentor through the 'helping' role and (2) enhanced skills and abilities to provide help, which fosters motivation to continue in the role of helping others. Riessman (1965) argues that through the 'helping' role, mentors take on new leadership roles and behaviours, improve their self-image and take on new roles that have social importance and status. More recently, self-help literature shows the peer mentor to have an influential role in assisting formerly incarcerated mentees to make concerted efforts to reconcile past harms (LeBel, Richie \& Maruna, 2015; Liem \& Richardson, 2014). Yet, as will be discussed below, peer mentoring programmes for justice-involved youth have been hesitant to include adults with a history of incarceration as peer mentors, and peer mentoring training models for adults with a history of incarceration have not fully considered the specific reparative processes and unique secondary desistance-oriented change needs of such adults before engaging in a mentoring role.

\subsection{Parallels in mental and behavioural health}

Peer mentoring is a key intervention among current mental and behavioural health recovery models adopted internationally (Repper \& Carter, 2011; Roberts et al., 1999; Tracy \& Wallace, 2016; White, 2000). Movements like Alcoholics 
Anonymous (AA) were among some of the first recovery models to argue that no one is in a better position to provide empathic, prosocial recovery support than a recovering person. AA was also one of the first models to introduce practices for making amends to the people who have been inadvertently harmed as key components to the recovery process (AA, 2001; White, 2000). The impetus for the broad use of peer mentorship in alcohol and substance misuse recovery is also rooted within the Community Reinforcement Approach (CRA) (Tracy \& Wallace, 2016). CRA models include peer mentoring foundations relating to an emphasis on prosocial roles that help to maintain abstinence (Tracy \& Wallace, 2016). Informed by the substance misuse community, recovery models in mental health seek to build on the resiliencies of individuals and emphasise consumer control in decision-making and are guided by the hope that it is possible for a person with mental health deficits to experience a meaningful life (Jacob, 2015). Mangrum's study (2009) with 424 US-based participants diagnosed with co-occurring substance misuse and psychiatric disorder substantiates the positive outcomes derived from peer support models. Results showed that participants who completed treatment were over 20 percent more likely to have received peer mentoring, and completion of the substance misuse programme was more likely the result of peer support more than any other type of support, including housing assistance.

Several researchers (Dwyer \& Maruna, 2011; Marsh, 2011) have noted congruencies between the current movement against the prison industrial complex and the long history of consumer-led movements. Both movements question the pervasiveness of pathology-driven labels and the sole use of 'medical model'-oriented treatments. The history of behavioural and mental health policy and practices is replete with approaches that failed to acknowledge the economic, social and structural barriers experienced by people with disabilities and recovery needs (Ayón \& Carlson, 2014). The literature also confirms that the disproportionate number of low-income, Black and Latino men within the prison system represents a significant factor in how the problem and response to mass incarceration is constructed (Alexander, 2012; Doherty \& Bersani, 2016; Livingston, Miller, Brunson \& Stewart, 2014). Analogous to the history of stigmatising policies and services for people with disabilities and recovery needs, the intersectionality of race and class has served to reinforce punitive policies and services that invest minimal resources in repairing the harm experienced by individuals with a history of incarceration.

Additionally, several researchers (Dwyer \& Maruna, 2011; Liem \& Richardson, 2014; Marsh, 2011) have compared CRA and recovery models in mental and behavioural health to the restorative justice and secondary-desistance oriented shifts in reintegration policy and practices. Consumer movements and allied authorities in mental and behavioural health have mobilised a shift away from a one-dimensional focus on treatment models provided by professional clinical experts (Milford, Austin \& Smith, 2007). Approaches in mental and behavioural health have moved towards comprehensive models of supportive care that attempt to destigmatise services, promote the empowerment of marginalised populations and enhance prosocial relationships. The unique strengths that peer 
mentors bring to behavioural and mental health provide a valuable parallel for peer mentoring models with justice-involved youth and desisting adult mentors.

\subsection{Peer mentoring and prosocial risks}

While peer support models in mental and behavioural health have gained legitimacy within US policymaking and programme development, the integration of desisting mentors has been met with significant resistance. Most state policies explicitly forbid individuals on parole to engage in a relationship with persons who have committed a crime, resulting in the hesitancy of many social service agencies and parole departments to recognise the unique value of credible messengers (Petersilia, 2003). Drawing on the extensive literature in criminology, many sociological theories, such as social learning, differential association, cultural deviance and social control, have successfully argued that criminal behaviour perpetuates through ongoing relationships with antisocial peers. Consequently, exposing justice-involved youth to desisting mentors is viewed as a risky endeavour with unpredictable outcomes (Akers, 1996; Durkheim, 1947; Hirschi, 1969). These risks should not be underestimated or overlooked in the screening and qualification process of credible messenger mentors. Equally important, the research on peer mentoring shows significant prosocial benefits for justiceinvolved youth participating in prosocial peer groups (Butts, Bazemore \& Meroe, 2010). Although the current models of assistance for justice-involved youth primarily focus on strategies to reduce deviant behaviour and risk exposure, a small number of peer mentoring programmes have also integrated practices that support the reparative needs and secondary desistance-oriented changes with justiceinvolved youth and adults (Austria \& Peterson, 2017; Maruna 2016).

\subsection{Peer mentoring model with justice-involved youth}

The Mentoring Center (TMC) in Oakland, California developed an early structure for credible messenger programmes (Jacks, 2000). The model implemented by TMC argues that credible messengers are the most qualified and empathic persons to support prosocial changes with hard-to-reach, high-risk youth. Transformative Mentoring programmes have replicated throughout the United States with some of the largest initiatives in New York City (NYC), Chicago, Illinois and Washington, DC (Tapia et al., 2013). Community Connections for Youth (CCFY), a New York City-based organisation that trains grassroots organisations in developing effective community-driven alternatives to incarceration for youth, has become a lead agent in strengthening and expanding the credible messengermentoring model through the New York City Department of Probation (DOP)'s ARCHES Transformative Mentoring Intervention (TMI) (Fazal, 2016). With over 800 justice-involved young adults (between 16 and 24 years old), and well over 100 credible messengers participating annually, the ARCHES TMI shows promising results, including a 50 percent reduction in felony rearrests among participants (Austria \& Peterson, 2017). 


\subsubsection{The ARCHES TMI}

The ARCHES TMI is comprised of six key components: (1) A prosocial group intervention that fosters a community of care; (2) A cognitive behavioural therapy (CBT) curriculum; (3) Formally assigned mentors who provide support, guidance and empathy; (4) Stipends for mentees and mentors; (5) The integration of positive youth development values and practices; and (6) Probation officers who provide case management services. Twice a week and over a 6 -month period, each mentor meets with five mentees for 90 minutes. ARCHES TMI sites are responsible for ensuring protocols for confidentiality, acquiring sufficient meeting space, hosting participants with a hot meal and providing coverage of participants' public transportation costs. Outside of scheduled meeting times, mentors are required to establish individual relationships with young adults through one-onone with mentees and weekly communication via text and phone calls.

\subsubsection{Credible Messenger Institute}

In 2011, the NYC DOP contracted CCFY to be its training and technical assistance provider for nineteen ARCHES TMI providers. Initiated by CCFY, the Credible Messenger Institute (CMI) serves as an access hub for curriculum development and training in addition to providing primary resource guidance to project coordinators in the practice of hiring, supervising and cultivating safe spaces for the ongoing support of credible messengers. A fundamental component of the CMI includes equipping project coordinators with the necessary processes for carefully screening potential mentors with standard background checks, as well as training on indigenous screening processes that make use of the references and recommendations from neighbourhood stakeholders (e.g. community helpers/activist, clergy, long-standing residents and neighbourhood police officers). The CMI also provides intake approaches that 'draw out' essential information needed for creating good mentors/mentee matches. It should be noted that hiring processes could have been impacted by selection bias, as it is not known whether mentors self-selected or if they 'qualified' for hiring.

Similar to credible messenger programmes across the country, the CMI provides over 80 hours training to prepare credible messengers with the skills and knowledge needed for mentoring mandated justice-involved youth. Mentors are trained on cognitive behavioural techniques, including the implementation of a CBT-based Interactive Journaling curriculum. The journaling intervention guides participants through a process for the successful change and maintenance of prosocial behaviours (Austria \& Peterson, 2017; Tapia et al., 2013). Additionally, the CMI prepares mentors with the skills needed to facilitate prosocial peer groups within a positive youth development framework. Grounding the training in positive youth development provides mentors with approaches for identifying and enhancing protective factors and supporting prosocial behaviours and relationships within the mentee's social networks (Butts et al., 2010). The mentors are also provided with training sessions on restorative justice peace circles. Such circles are used to assist justice-involved youth in accepting accountability for offences and addressing the harm and conflict within relationships (e.g. victims, family members and local neighbours) (Coates, Umbreit \& Vos, 2003). These ses- 
sions prepare mentors with peace-making skills and the knowledge needed to empathically engage as community participants within the restorative circle processes with their mentees.

\subsection{Secondary desistance needs of mentors and the development of a training model}

During the initial training phase of the credible messengers, the CMI project coordinators and training facilitators observed that additional supports were needed to meet the distinctive professional and personal development needs of the credible messengers. As wounded healers, credible messengers often carry unaddressed trauma and, when left unaddressed, these wounds can threaten the credible messenger's ability to support a young person's growth and well-being. Additionally, if stressors cause a relapse into old patterns of behaviours, these relapses may threaten the restorative justice opportunities within the peer mentoring relationship (Esping, 2013; Maruna, 2016). The Howard League's (Bright, 2015) evaluation of a peer mentoring programme with returning citizens substantiated a significant limitation of the programme as the lack of ongoing quality training and supervision to support the mentors' development of personal resiliencies. Similarly, the CMI directors and developers found few evidence-based resources that could support the internal needs of the desisting mentors. Austria and Peterson (2017: 8) poignantly note the quality and content of support needed by mentors through the following statement:

[...] it is not to suggest that credible messengers need heavier supervision or closer monitoring, but rather that the practice of paying attention to the work, assessing strengths and weaknesses, working with each individual on areas of professional development and developing strong supportive relationships between mentors and supervisors is essential for success.

The personal narratives of the mentors and their empathy towards the struggles of adjudicated youth are a unique opportunity for restorative service that produces tangible good through prosocial relationships with justice-involved youth. Equally important, local communities often benefit from greater levels of safety and the expansion of available prosocial networks (Dwyer \& Maruna, 2011). However, holding such unique traits increase the need for ongoing, comprehensive training that supports the mentors' progression towards secondary desistance-oriented changes and a healing process that addresses the harm experienced by the mentor. On the basis of the identified needs of the mentors, a new training programme was developed to support mentors before they embarked on their role as credible messengers to justice-involved youth. The following section presents the innovative peer mentoring training model aimed to support primary and secondary desistance-related changes and foster restorative justice practices among the credible messengers. 


\section{Figure 1 Desistance model for peer mentoring training}

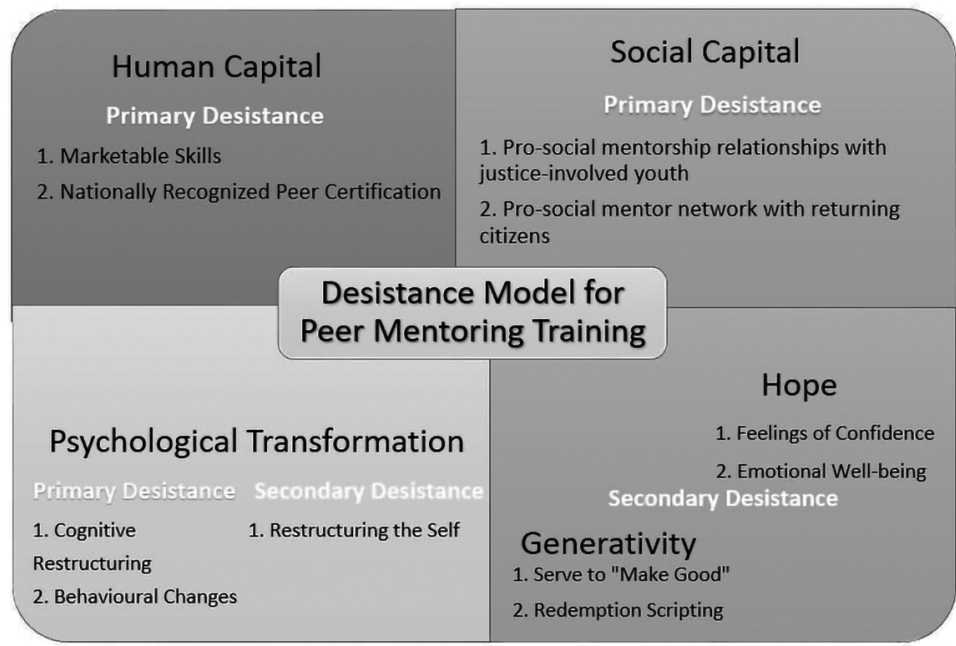

\section{Model for peer mentoring training}

The key components of the peer mentoring training model for supporting desistance-related changes and restorative justice practices are depicted in Figure 1. The CMA's original training content addressed many of the essential professional skills components for promoting primary desistance and restorative justice practices that work towards repairing the social harm inflicted by crime. The additional 6-week training, as detailed in Table 1, focused on the development of the internal changes needed for secondary desistance and restorative justice practices for supporting mentors in addressing the individual harm caused by crime. As Figure 1 and Table 1 illustrate, the 6-week training model consists of the following essential components for supporting primary desistance and secondary desistance changes for credible messengers: (1) Human Capital, (2) Social Capital, (3) Psychological Transformation, and (4) Hope and Generativity, which will be discussed in more detail below. 


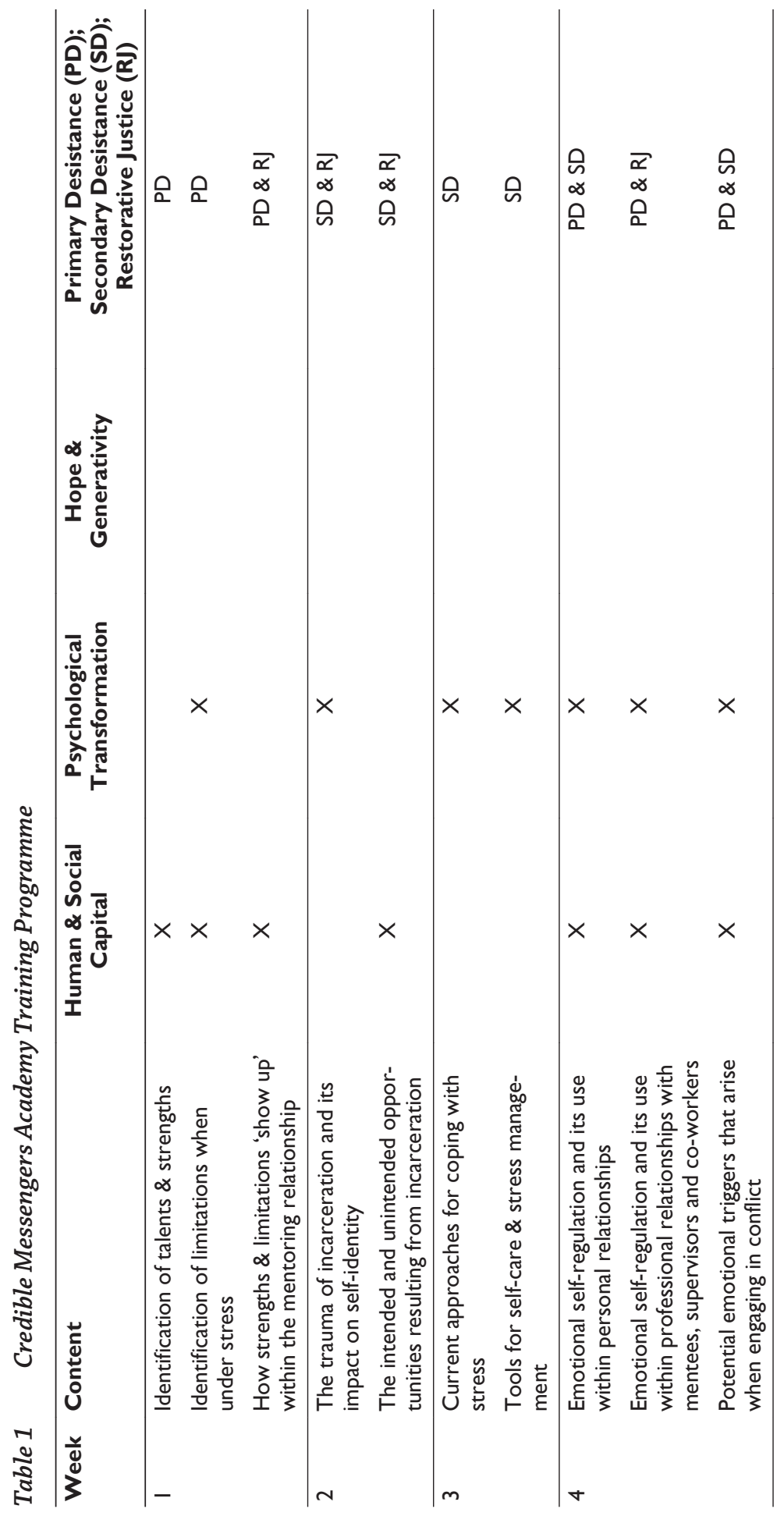




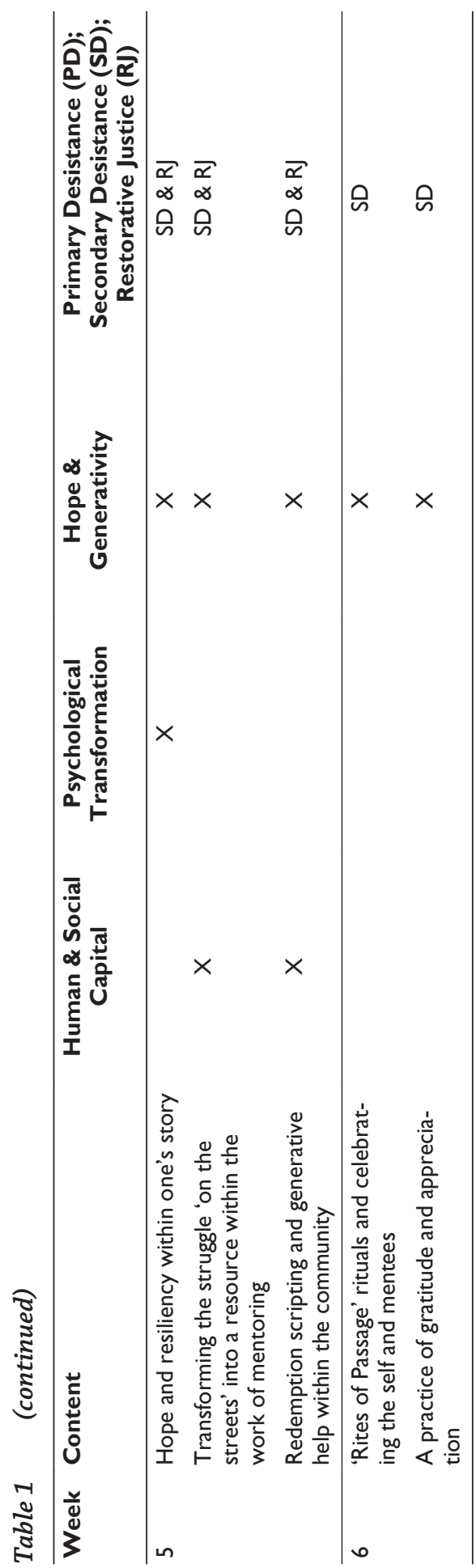




\subsection{Human and social capital}

Increasing human and social capital can begin the desistance processes and serve as critical factors to sustaining desistance among individuals who were formerly incarcerated (Farrall, 2004; McNeill, 2009). For example, Farrall and Sparks (2006: 11) state:

Those most likely to be negotiating life after punishment are therefore also amongst those most likely to have limited legitimate resources both regarding their human capital (i.e. their skills) and in terms of the skills and knowledge which permeate the communities in which they live (their social capital).

For most who hold a criminal record, minimal experiences with prosocial adult milestones, such as stable housing, high school graduation and raising a family, often result in deficiencies in healthy, thriving social networks (Bauldry \& Hartmann, 2004). Similarly, Lynch, William, Sabol and Shelley (2001) found experiences with incarceration to weaken one's participation in family bonding functions, volunteer associations and civic affiliations. Conversely, prosocial experiences serve to reduce social isolation and increase desistance (Settles, 2009). Equally important, a significant contributor to cultivating social capital that motivates a process for ongoing desistance includes opportunities for adults to receive ongoing support with fellow peer mentors who also have a history of incarceration. Adair's (2005: 15) report on peer support among persons who were currently imprisoned holds that the social value of fellow peer mentor relationships.

[...] can do more than ameliorate the 'de-socialising' effects of imprisonment. The trust and openness that can be facilitated among the peer support team members in the course of a group work oriented training process and subsequent maintenance meetings are likely to be unique in many participants' lives.

Peer mentors also share a common desire to practice roles that publically substantiate that they are worthy of forgiveness (LeBel et al., 2015). As a result, the mentor's participation in restorative service is also a contribution that works towards repairing the social harm caused by past offences.

As Table 1 illustrates, the training model focuses on group processes and shared experiences where mentors are encouraged to tell their stories and work together to reinforce a new positive identity that highlights the strengths, knowledge and skills that they can bring to the mentor role and new identity of 'wounded healer' and 'credible messenger'. Such mutuality fosters non-judgemental support and empathy through a 'shared experience' and facilitates the opportunity for positive changes to result from the discovery of a productive shared identity (Curtis, Marcus \& Jacobs, 2013). The prosocial changes resulting from the shared identity of 'peer mentor' include the mentor's expansion of new forms of social capital. The identity of credible messenger gives evidence of the mentor's redemptive change to local social networks (i.e. community residents, business owners and authorities) by tangibly demonstrating the mentor's restorative con- 
tributions towards the 'social rehabilitation' of their community (Maloney, Bazemore \& Hudson, 2001; Mead, Hilton \& Curtis, 2001).

For adults who were incarcerated, social and human capital levels can be underdeveloped by disruptions in educational attainment and limited participation in a lawful labour market (Holzer \& Martinson, 2005). Some studies evaluating vocational and educational programmes with re-entry participants show limited increases in desistance (Aos, Miller \& Drake, 2006). However, Visher, Knight, Chalfin and Roman (2009) argue that education and training programmes with low-wage workers are most successful when they lead to credentials that meet market demands. The CMI is a valuable example of training that imparts marketable skills, such as group facilitation, interpersonal engagement, non-judgemental listening, cognitive-behavioural approaches and peacemaking. The training and subsequent employment of adults with a history of incarceration as credible messengers provides the mentors with opportunities to expand employment prospects and prosocial networks through their ongoing involvement with community-based organisations, civic and criminal justice authorities and rehabilitation professionals. Additionally, credible messengers can leverage the skills and knowledge they have gained as peer mentors and market themselves beyond their roles as a peer mentor by specifying and/or demonstrating how their skills as a peer mentor can be transferred to other professional relationships and forms of employment.

Some studies suggest that a credentialing peer mentoring training for desisting mentors would assist in standardising best practices in peer mentorship, while concurrently meeting the labour market's need for mentors who are credible and skilled in mentoring high-risk youth (Bright, 2015; Huggins, 2010). Although the certified peer specialist workforce is relatively new, mental and behavioural health fields have increasingly made use of credentialed peer navigators. In all these cases, remunerated assistance from individuals with similar lived experiences is recognised as a valuable service, and has grown to include more professionalised, credentialed positions such as the Certified Alcohol and Substance Abuse Counselor and the Behavioral Health Peer Navigator (Chapman, Blash \& Chan, 2015; Hagedorn, Culbreth \& Cashwell, 2012). A credentialing process provides an element of professional authority and external validation to a role that also enhances the mentor's human and social capital. For example, human capital can be enhanced and fostered by providing a productive role for the mentors that refutes the identity of 'offender' and 'threat to society' and develops an identity of an engaged citizen who contributes to the healing of a community. Social capital can be further enhanced through formalised networks of employment, continuing education and access to community-based services and resources that have not been readily available or accessible to adults who were formerly incarcerated.

\subsection{Psychological transformation}

Correcting cognitive distortions is often the antecedent to behavioural changes that augment social and human capital outcomes (Taxman \& Thanner, 2006). Therefore, the training model prepares mentors with a basic knowledge of cogni- 
tive distortions and an Interactive Journaling change tool for identifying and correcting cognitive distortions that can work as barriers in the reconstruction of one's identity, role and presentation of themselves (see Table 1). Cognitive distortions occur when an individual's thinking leads to inaccurate and unreasoned conclusions (Moore, Milam, Folk \& Tangney, 2017). For many persons with a history of incarceration, cognitive distortions can influence destructive behaviour patterns that contribute to recidivism (Maruna \& Mann, 2006). For example, 'Black and White' thinking or rigid 'all or nothing' thought patterns often prevent an individual from viewing the positive and negative aspects of the self and others. When a person with a history of incarceration rigidly concludes that he or she will always be a 'criminal', this black and white distortion can impede an individual's capacity to separate his or her criminal record from the totality of self-identity (Moore et al., 2017). The studies of CBT interventions that aim to modify thoughts, feelings and actions that lead to psychological distress and negative behaviours demonstrate success in reducing cognitive distortions and sustaining non-offending behaviour. For example, Landenberger and Lipsey's (2005) metaanalysis of fourteen studies found that the recidivism rates for CBT participants were 27 percent lower than non-participants, thus, demonstrating the effectiveness of CBT in psychological transformations of thoughts, feelings and behaviours. Such psychological transformations enhance the mentor's role with justiceinvolved youth by providing an empathic modelling of the approaches and internal benefits of engaging in psychological changes that broaden one's identity and contribute to one's motivation towards ongoing desistance.

Incorporating CBT approaches into the training model is fundamental to initiating secondary-desistance change processes that link the restructuring of thoughts, feelings and behavioural patterns to the reorganisation of one's identity (Maruna, 2001). Research supports the use of peer mentorship as an intervention that provides individuals with opportunities to practice a new role that broadens one's self-identity, increases confidence and helps with desistance; elements of the 'helper' therapy principle (Adair, 2005; LeBel, 2007); thus, this process should begin within the training programme for mentors. When individuals with a history of incarceration experience a disruption in their current roles, a reorganisation of the self on the basis of their emerging new roles can initiate the beginnings of secondary desistance change processes (LeBel, 2007). Often, individuals who are involved in correctional systems have practised and internalised an identity that is experienced only via a limited number of reinforced deficitbased roles (e.g. 'criminal'). According to Veysey, Martinez and Christian (2009), developing new identities that broaden one's perceptual framework of the self requires opportunities for desisters to practice new prosocial, self-esteem enhancing roles such as supportive father or educator. Equally important, narratives are a representation of a person's identity and restorative justice practices can foster narratives of change (Maruna, 2016). An ongoing practice in these new restorative roles increases the desister's opportunities to engage in prosocial, identity enhancing networks and resources. Developing a new identity does not come with the expectation that mentors lose or ignore their past, but rather use their traumatic experiences as a source of resiliency to 'make good' and reinforce a new 
identity (Maruna, 2001) through their restorative work with justice-involved youth. Unfortunately, little research has examined how supports for peer mentors could strengthen the internal restructuring of their self-identity and provide external opportunities for peer mentors to 'make good' of their experiences with incarceration.

\subsection{Hope and generativity}

Adjusting distorted thinking patterns and strengthening self-identity positively affects the motivations of individuals who are in the process of desistance. However, addressing motivations alone does not facilitate hope for a future. Lopez, Snyder and Pedrotti (2003) describe emotion-based models of hope, 'as being a reinforcing affective state that is used to propel individuals towards goals but can also be used as a coping mechanism in dire situations' (as cited in Martin \& Stermac, 2010: 694). In addition, cognitive-based models of hope assert that thoughts and beliefs provide agency for hope that supports the achievement of one's goals (Martin \& Stermac, 2010). A study of retrospective qualitative data (Farrall \& Calverley, 2006) substantiates hope as an emerging key variable in providing adults who were incarcerated with feelings of confidence that influence positive choicemaking and exercising control over their lives. For some desisters, the agency provided by hope has its inception in human and social capital (e.g. the hopes of finding a meaningful job or the hope of reconciling with a family member). While for other desisters, spirituality and/or religion provided an indispensable disruption from stressors related to continuing desistance and an external reinforcement of moral, socially acceptable behaviour (Maruna, 2006). Therefore, the training model provides mentors with practices that can foster hope and generativity (see Table 1).

Hope and generativity are critical aspects to the peer mentoring role as Repper and Carter (2011) argue that peer mentors are better at encouraging hope and the belief in possible recovery than their non-peer counterparts. A limited number of studies support experiences with hope as a key influencer in desisters 'trying on' positive roles and identities that offer opportunities to 'make good' (Lloyd \& Serin 2011; Maruna \& Farrall, 2004). Notably, in Maruna's (2001) qualitative research with adults with continuous desistance, emergent themes related to 'making good' were identified as experiences that facilitated the emergence of hopeful self-stories and contributed to a 'redemption script.' Similarly, modules within the training model include oral, visual and written approaches that encourage mentors to recognise and share their hopeful self-stories. Informed by the restorative justice principles of ritualising repair within a relational framework (e.g. sentencing circles and family-group conferencing), the redemption scripting process is not a solitary exercise, but rather a communal ritual that is shaped and honed within a forum of peer support (Maruna, 2016). The 'telling' of these hopeful self-stories facilitates a redemption scripting process that provides opportunities for the desisting adult to demonstrate and affirm the cultivation of a 'real' identity - an essentially good personhood. Redemption scripting also 'justifies' or 'normalises' an interpretation of the mentor's incarceration resulting from an ecology of structural trauma (e.g. poverty and racism) and disadvantages 
(e.g. limited social networks and unsupported mental health needs), without negating the harms committed (Maruna, 2001). The redemptive scripting process (Maruna, 2001: 245 as cited in Veysey et al., 2009):

[b]egins by establishing the goodness and conventionality of the narrator - a victim of society who gets involved with crime and drugs to achieve some sort of power over otherwise bleak circumstances ... Newly empowered, he or she now also seeks to 'give something back' to society as a display of gratitude.

The cognitive restructuring of deviant roles and identities is mostly connected to 'making good' through generative helping work roles (e.g. parenthood and peer mentoring) and identities (e.g. 'wounded healer') that provide not only an opportunity to desist, but also roles and identities that require desistance for successful performance (LeBel, Richie \& Maruna, 2015). McAdams and de St. Aubin (1998 as cited in Maruna \& LeBel, 2009: 132) describe generativity as 'the concern for and commitment to promoting the next generation, manifested through parenting, teaching, mentoring'. Confirming the importance of generative identities and roles, LeBel et al. (2015) study of 258 adults participating in re-entry-related services found that participants who reported employment in a helping role, such as a counsellor, showed higher self-esteem and greater life satisfaction than participants who were not employed in a helping role. An ethnographic study also revealed how the mentor's role modelling of generative behaviours could awaken within the mentee a 'desire to give to others: "they were offering help to other people. ... I wanted to be able to do that"' (Buck, 2016: 7). More important than the desire inspired, is the mentee's opportunity to practice planning for possible future directions. The mentor's generative helping role can become the basis of a viable model for the mentee's future life plans (Buck, 2016).

Restorative justice practices are often studied from the perspective of returning citizens acknowledging and making amends with the individuals who were harmed. However, the sole use of interpersonal forms of restorative justice does not address the 'social rehabilitative' work that is needed to restore the damage done to the communities. Through the peer mentoring training and the subsequent practice as a peer mentor, mentors are provided with a generative pathway for returning to their communities. In the role of credible messenger, mentors can now practice a restorative service that works towards repairing the social harm by supporting youth in pursuing meaningful, nonrecidivating, alternatives to criminal behaviour. The training and certification process required to practice the new role of 'peer mentor' also provides local community members with a public endorsement that the individual is no longer practising the identity of a 'deviant liability', but rather an identity of 'resourceful, transformed citizen' (McNeill, 2006). 


\section{Implications for research and practice}

Given the sizeable financial investments made every year to fund the study of effective interventions that can reduce recidivism, it is astounding to find so little research on peer mentoring interventions. Further research is needed to understand the inner workings of peer mentoring and how/if it can be a restorative experience that produces secondary desistance-oriented change outcomes for both justice-involved youth and desisting adult mentors as well as identifying the specific conditions that support and promote mentors' reparation towards the community. The literature on peer mentoring training with justice-involved adults often places a primary focus on supporting the RNR aspects of successful desistance; however, peer mentoring training models cited in the literature did not include approaches for supporting secondary desistance-oriented change processes or inclusive restorative justice approaches that address the individual harm experienced by the offender. Researchers should seek to investigate the mediating and correlating processes that could facilitate secondary desistance changes within peer mentoring trainings/on-going supervision. If peer mentoring can indeed be an effective model for secondary desistance-oriented changes, longitudinal research that combines qualitative and quantitative approaches are needed to provide a more in-depth examination of the implicit and explicit mechanisms underlying the intervention and the conditions that support and promote reparation towards the community. Comprehensive programme descriptions within studies could also provide a baseline assessment of the mentor/mentees human and social capital, the development process and content of mentor training, organisational arrangements that sustain equitable and productive relationships between 'professional' staff and credible messengers and specifics about how mentors are supported with ongoing supervision. Lastly, there is a significant gap in the study of the local community's restorative role in recognising and sanctioning the generative practices and self-identity changes within mentors and mentees.

Developing a national credentialing qualification for credible messengers could assist in the formalising of mentoring skills and supports. Equally important, a national credentialing qualification could expand the mentor's employment marketability within the youth services sector, thus further enhancing social and human capital. For example, in the United States, a few states have targeted youth as a population to be served by Medicaid-funded peer support specialists (Simons \& Mahadevan, 2012). A participatory approach inclusive of mentors and mentees could serve to inform the development of a credentialing for desisting mentors that is not 'overly professionalised' by formal experts and continues to leverage the unique strengths derived from the narratives of credible messengers. Similarly, Mead and MacNeil (2006: 30) posit, 'a non-professional vantage point is crucial in helping people rebuild their sense of community when they've had a disconnecting kind of experience'. 


\section{Conclusion}

Secondary desistance approaches provide opportunities to enhance the standard offerings of risk/needs support models. Evidence-based peer mentoring models and training programmes, with innovative approaches for supporting secondary desistance-orientated changes and restorative justice practices, could provide opportunities for justice-involved youth and desisting adults to develop a generative, restructured self-identity that contributes to long-term flourishing and healing of the communities in which they live. While some peer mentoring programmes prepare mentors with skills and interventions to support primary desistance with justice-involved youth, there is less guidance on mentoring models that focus on secondary desistance and the reparative needs of the mentors. An evidence-based peer-training model that supports the cultivation of human and social capital, psychological transformation, hope and generativity is presented in this article. The authors argue that a peer mentoring training model that supports the internal needs of mentors and externally promotes generative helping roles that contribute to the social rehabilitation of local communities can provide the basis for primary and secondary desistance changes with justice-involved youth and adults with a history of incarceration.

\section{References}

Adair, D. (2005). Peer support programs within prisons. Tasmania: University of Tasmania School of Sociology and Social Work.

Akers, R. (1996). Is differential association/social learning cultural deviance theory? Criminology, 34(2), 229-247.

Alcoholics Anonymous (2001). Alcoholics Anonymous: the story of how many thousands of men and women have recovered from alcoholism (4th ed.). New York City: Alcoholics Anonymous World Services.

Alexander, M. (2012). The new Jim Crow: mass incarceration in the age of colorblindness. New York: The New Press.

Aos, S., Miller, M. \& Drake, E. (2006). Evidence-based adult corrections programs: what works and what does not. Olympia: Washington State Institute for Public Policy.

Austria, R. \& Peterson, J. (2017). Credible messenger mentoring for justice-involved youth. Retrieved from: www.thepinkertonfoundation.org/wp-content/uploads/2017/02/ Pinkerton-Papers-credible-messenger-monitoring.pdf (last accessed 24 November 2017).

Ayón, C. \& Carlson, B. (2014). A family affair: Latinas' narratives of substance use and recovery. Journal of Ethnic \& Cultural Diversity in Social Work, 23(1), 55-77.

Baker, D.B. \& Maguire, C. (2005). Mentoring in historical perspective. In D.L. Dubois \& M.J. Karcher (eds.), Handbook of youth mentoring (pp. 454-466). Thousand Oaks: Sage.

Bauldry, S. \& Hartmann, T.A. (2004). The promise and challenge of mentoring high-risk youth: findings from the National Faith-Based Initiative. Philadelphia: Public/Private Ventures.

Bilchik, S. (1998). Juvenile Mentoring Program (JUMP): 1998 report to Congress. Retrieved from: https://www.ncjrs.gov/pdffiles1/952872.pdf (last accessed 24 November 2017).

Bonta, J. \& Andrews, D.A. (2017). The psychology of criminal conduct (6th ed.). New York: Routledge. 
Bright, J. (2015). Takes one to know one: an evaluation of peer mentoring in the drug dependency treatment sector. London: The Howard League for Penal Reform.

Buck, G. (2016). 'I wanted to feel the way they did': mimesis as a situational dynamic of peer mentoring by ex-offenders. Deviant Behavior, 38(9), 1-15.

Butts, J.A., Bazemore, G. \& Meroe, A.S. (2010). Positive youth justice: framing justice interventions using the concepts of positive youth development. Washington, DC: Coalition for Juvenile Justice.

Chapman, S., Blash, L. \& Chan, K. (2015). The peer provider workforce in behavioral health: a landscape analysis. San Francisco: UCSF Health Workforce Research Center on LongTerm Care.

Coates, R., Umbreit, M. \& Vos, B. (2003). Restorative justice circles: an exploratory study. Contemporary Justice Review, 6(3), 265-278.

Curtis, R., Marcus, A. \& Jacobs, N. (2013). South Bronx Community Connections: a pilot project of Community Connections for Youth: a grassroots approach to pro-social development in a neighborhood of chronic disadvantage. Retrieved from: http://snrg-nyc.org/ wpcontent/uploads/2017/06/SBCC_Technical_Report.pdf (last accessed 24 November 2017).

Doherty, E., \& Bersani, B. (2016). Understanding the mechanisms of desistance at the intersection of race, gender, and neighborhood context. Journal of Research in Crime and Delinquency, 53(5), 681-710.

Douglas, E. \& Delgado, S. (2014). Most high-risk youth referred to Youth Advocate Programs, Inc. remain arrest free and in their communities during YAP participation. New York City: Research \& Evaluation Center, John Jay College of Criminal Justice.

Durkheim, E. (1947). The division of labor in society. Glencoe: Free Press.

Dwyer, C.D. \& Maruna, S. (2011). The role of self-help efforts in the reintegration of 'politically motivated' former prisoners: implications from the Northern Irish experience. Crime, Law, and Social Change, 55, 293-309.

Esping, A. (2013). From 'at-risk' youth to wounded healer: a longitudinal study of two pre service teachers. International Journal of Qualitative Studies in Education, 27(3), 377-396.

Farrall, S. (2004). Social capital and offender reintegration: making probation desistance focused. In S. Maruna \& R. Immarigeon (eds.), After crime and punishment: pathways to offender reintegration (pp. 57-82). Portland: Willan Publishing.

Farrall, S. \& Calverley, A. (2006). Understanding desistance from crime: theoretical directions in rehabilitation and resettlement. Maidenhead: Open University Press.

Farrall, S. \& Sparks, R. (2006). Introduction. Criminology \& Criminal Justice: An International Journal, 6(1), 7-17.

Fazal, S. (2016, July 15). A much-needed alternative to youth prisons. Retrieved from: https:// www.huffingtonpost.com/shaena-fazal/youth-prisons_b_7772722.html (last accessed 24 November 2017).

Hagedorn, W., Culbreth, J. \& Cashwell, C. (2012). Addiction counseling accreditation: CACREP's role in solidifying the counseling profession. The Professional Counselor, 2(2), 124-133.

Hirschi, T. (1969). Causes of delinquency. Berkeley: Free Press.

Holzer, H. \& Martinson, K. (2005). Can we improve job retention and advancement among low-income working parents? Washington, DC: Urban Institute Press.

Huggins, R. (2010). Mentoring for Progression: Prison Mentoring Project- Assessing Strengths, Outcomes and Roll-Out Potential. London: Howard League for Penal Reform.

Jacks, M. (2000). The Mentoring Center's philosophy and opinions. Oakland: The Mentoring Center. 
Jacob, K.S. (2015). Recovery model of mental illness: a complementary approach to psychiatric care. Indian Journal of Psychological Medicine, 37(2), 117-119.

Landenberger, N.A. \& Lipsey, M.W. (2005). The positive effects of cognitive-behavioral programs for offenders: a meta-analysis of factors associated with effective treatment. Journal of Experimental Criminology, 1(4), 451-476.

LeBel, T. (2009). Formerly incarcerated persons' use of advocacy/activism as a coping orientation in the reintegration process. In B. Veysey, J. Christian \& D. Martinez (eds.), How offenders transform their lives. Cullompton: Willan Publishing.

LeBel, T.P. (2007). An examination of the impact of formerly incarcerated persons helping others. Journal of Offender Rehabilitation, 46(1/2), 1-24.

LeBel, T.P., Richie, M. \& Maruna, S. (2015). Helping others as a response to reconcile a criminal past: the role of the wounded healer in prisoner reentry programs. Criminal Justice and Behavior, 42(1), 108-120.

Liem, M. \& Richardson, N.J. (2014). The role of transformation narratives in desistance among released lifers. Criminal Justice and Behavior, 41, 692-712.

Livingston, L., Miller, J., Brunson, R.K. \& Stewart, E.A. (2014). Inequalities of race, class, and place and their impact on post incarceration higher education. Race and Justice, 4(3), 212-245.

Lloyd, C.D. \& Serin, R.C. (2011). Agency and outcome expectancies for crime desistance: measuring offenders' personal beliefs about change. Psychology, Crime \& Law, 18(6), 543-565.

Lopez, S.J., Snyder, C.R. \& Pedrotti, J.T. (2003). Hope: many definitions, many measures. In S.J. Lopez \& C.R. Snyder (eds.), Positive psychological assessment: a handbook of models and measures (pp. 91-106). Washington, DC: American Psychological Association.

Lynch, J.P., William J., Sabol, P. \& Shelley, M. (2001). Crime, coercion, and community: the effects of arrest and incarceration policies on informal social control in neighborhoods. Washington, DC: Urban Institute Justice Policy Center.

Maloney, D. (2007). Restorative community service: earning redemption, gaining skills and proving worth. Reclaiming Children and Youth, 15, 214-219.

Maloney, D., Bazemore, G. \& Hudson, J. (2001). The end of probation and the beginning of community corrections. Perspectives, 4, 23-30.

Mangrum, L.F. (2009). Client and service characteristics associated with addiction treatment completion of clients with co-occurring disorders. Addictive Behaviors, 34, 898-904.

Marsh, B. (2011). Narrating desistance: identity change and the 12 step script. Irish Probation Journal, 8, 49-68.

Martin, K. \& Stermac, L. (2010). Measuring hope. International Journal of Offender Therapy and Comparative Criminology, 54(5), 693-705.

Maruna, S. (2001). Making good: how ex-convicts reform and rebuild their lives. Washington, DC: American Psychological Association.

Maruna, S. (2006). Who owns resettlement? Towards restorative re-integration. British Journal of Community Justice, 4(2), 23-33.

Maruna, S. (2016). Desistance and restorative justice: it's now or never. Restorative Justice: An International Journal, 4(3), 289-301.

Maruna, S. \& Farrall, S. (2004). Desistance from crime: a theoretical reformulation. Koelner Zeitschrift fur Soziologie und Sozialpsychologie, 43, 171-194.

Maruna, S. \& LeBel, T. (2009). Strengths-based approaches to reentry: extra mileage toward reintegration and destigmatization. Japanese Journal of Sociological Criminology, 34, 58-80. 
Maruna, S. \& Mann, R.E. (2006). A fundamental attribution error? Rethinking cognitive distortions. Legal and Criminological Psychology, 11(2), 155-177.

McAdams, D.P. \& de St. Aubin, E. (1998). Generativity and adult development: how and why we care about the next generation. Washington, DC: American Psychological Association.

McNeill, F. (2006). A desistance paradigm for offender management. Criminology and Criminal Justice, 6, 39-62.

McNeill, F. (2009). What works and what's just? European Journal of Probation, 1(1), 21-40.Mead, S., Hilton, D. \& Curtis, L. (2001). Peer support: a theoretical perspective. Psychiatric Rehabilitation Journal, 25(2), 134-141.

Mead, S. \& MacNeil, C. (2006). Peer support: what makes it unique? International Journal of Psychosocial Rehabilitation, 10(2), 29-37.

Milford, J.L., Austin, J.L. \& Smith, J.E. (2007). Community reinforcement and the dissemination of evidence-based practice: implications for public policy. International Journal of Behavioral Consultation and Therapy, 3(1): 77-87.

Moore, K., Milam, K., Folk, J., \& Tangney, J. (2017). Self-stigma among criminal offender risk and protective factors. Stigma and Health. Retrieved from: https://www.ncbi.nlm. nih.gov/pmc/articles/PMC5067087/(last accessed 1 November 2017).

Petersilia, J. (2003). When prisoners come home: parole and prisoner reentry. New York: Oxford University Press.

Prince's Trust. (2008). Making the case for one to one support for young offenders. Retrieved from: https://www.clinks.org/making-the-case (last accessed 2 January 2018).

Repper, J. \& Carter, T. (2011). A review of the literature on peer support in mental health services. Journal of Mental Health, 20(4), 392-411.

Riessman, F. (1965). The 'helper' therapy principle. Social Work, 10(2), 27-32.

Roberts, L., Salem, D., Rappaport, J., Toro, P., Luke, D. \& Seidman, E. (1999). Giving and receiving help: interpersonal transactions in mutual-help meetings and psychosocial adjustment of members. American Journal of Community Psychology, 27(6), 841-865.

Settles, T. (2009). Restorative reentry: a strategy to improve reentry outcomes by enhancing social capital. Victims \& Offenders, 4(3), 285-302.

Simons, D. \& Mahadevan, R. (2012). Medicaid financing for family and youth peer support: a scan of state programs. Retrieved from: https://www.chcs.org/media/Family-YouthPeer-Support-Matrix-reformatted-070714.pdf (last accessed 24 November 2017).

Tapia, M., Alarid, F.L. \& Enriquez Jr., A. (2013). Court-ordered mentoring programs for adjudicated juveniles: when should youth be referred? Justice Policy Journal, 10(2), 1-18.

Taxman, F.S. \& Thanner, M. (2006). Risk, need, responsivity (RNR): it all depends. Crime \& Delinquency, 52(1), 28-51.

Tracy, K. \& Wallace, S.P. (2016). Benefits of peer support groups in the treatment of addiction. Substance Abuse and Rehabilitation, 7, 143-154.

Veysey, B., Martinez, D.J. \& Christian, J. (2009). Identity transformation and offender change. In B. Veysey, J. Christian \& D.J. Martinez (eds.), How offenders transform their lives (pp. 1-11). Cullompton: Willan Publishing.

Visher, C., Knight, C., Chalfin, A. \& Roman, J. (2009). The impact of marital \& relationship status on social outcomes for former prisoners. Washington, DC: Urban Institute.

Walgrave, L. (2008). Restorative justice, self-interest, and responsible citizenship. Cullompton: Willan Publishing.

Walker, S., Pullmann, M. \& Trupin, E. (2012). Juvenile justice 101: addressing family support needs in juvenile court. OJJDP Journal of Juvenile Justice, 2(1), 54-67. 
Ward, T., Fox, A. \& Garber M. (2014). Restorative justice, offender rehabilitation, and desistance. Restorative Justice: An International Journal, 2(1), 24-42.

Weaver, B. \& Lightowler, C. (2012). Shaping the criminal justice system: the role of those supported by criminal justice services. Retrieved from: https://www.iriss.org.uk/resources/ insights/shaping-criminal-justice-system-role-those-supported-criminal-justiceservices (last accessed 24 November 2017).

White, W. (2000). The history of recovered people as wounded healers: II. The era of professionalization and specialization. Alcoholism Treatment Quarterly, 18(2), 1-25. 